\title{
O setor hoteleiro e o marketing de relacionamento: um estudo de caso na cidade de Belo Horizonte - Minas Gerais, Brasil
}

\author{
The hotel industry and relationship marketing: The case of Belo Horizonte - Minas \\ Gerais, Brazil
}

\author{
João Carlos Ferreira Bronze Júnior (BRONZE JÚNIOR, J. C. F.)* \\ Caissa Veloso e Sousa (SOUSA, C. V. e) ${ }^{* *}$ \\ José Edson Lara (LARA, J. E.) \\ André Francisco Alcântara Fagundes (FAGUNDES, A. F. A.) ${ }^{* * * *}$ \\ Danilo de Oliveira Sampaio (SAMPAIO, D. O.) (**** $^{\text {(SA }}$
}

\begin{abstract}
RESUMO - Considerando a proximidade de importantes eventos de nível internacional a serem realizados em Belo Horizonte (Minas Gerais, Brasil), e o aumento na demanda por hospedagem na cidade, o presente artigo busca, por meio de um estudo de caso sobre um hotel quatro estrelas, identificar aspectos das estratégias de marketing de relacionamento passíveis de representar vantagem competitiva para a organização. Foram entrevistados 120 hóspedes e 15 empregados do grupo hoteleiro, por meio de questionários estruturados aplicados nos meses de outubro e novembro de 2011. Os resultados do estudo apontaram que 74,7\% das reservas do hotel são provindas de clientes que já haviam se hospedado anteriormente no local, sendo que esses clientes, em diferentes níveis, participaram do programa de marketing de relacionamento do hotel. Ademais, são apresentados resultados que descrevem o nível de satisfação desses hóspedes e a propensão deles em indicar o hotel para outras pessoas. Dessa forma, acredita-se que as estratégias oriundas do marketing de relacionamento possibilitaram um resultado positivo e elevaram a competitividade da organização frente ao mercado.
\end{abstract}

Palavras-chave: Marketing de Serviços; Marketing de Relacionamento; Vantagem Competitiva.

ABSTRACT - Considering the proximity of important international events to be held in Belo Horizonte (MG), and increased demand for accommodation in the city, this article aims, through a case study in a four stars hotel, identify aspects of relationship marketing strategies that could represent a competitive advantage for the organization. It was interviewed 120 hotel guests and 15 group hotel employees using structured questionnaires applied in October and November of 2011 . The results showed that $74.7 \%$ of hotel bookings were from customers who had previously stayed in the hotel, and these customers, at different levels, participated in the organization relationship marketing program. Furthermore, the results describe the level of satisfaction of the guests and their propensity to indicate the hotel to others. Thus, it is believed that the strategies derived from the relationship marketing enabled a positive outcome and increased the competitiveness of the organization.

Keywords: Services Marketing; Relationship Marketing; Competitive Advantage.

\footnotetext{
* Graduação em Administração de Empresas (Bacharelado) pela Faculdade de Estudos Administrativos - FEAD/MG. Endereço para correspondência: Rua João Fernandes de Oliveira, 150 - Bloco 7 - ap. 304 - Bairro Planalto. CEP: 31730-620 - Belo Horizonte MG (Brasil). Telefone: (31) 8531-6272. E-mail: bronzejunior@yahoo.com.br

** Graduação em Economia pela Pontifícia Universidade Católica de Minas Gerais (PUC/Minas). Mestrado em Administração de Empresas pela FEAD/MG. Doutorado em Administração de Empresas pela Universidade Federal de Minas Gerais - UFMG. Professora do Mestrado em Administração da Faculdade Novos Horizontes. Endereço para correspondência: Rua Dom Joaquim Silvério, 921 - ap. 404 - Bairro Coração Eucarístico - Belo Horizonte - MG (Brasil). CEP: 30535-620. Telefone: (31) 9337-4933. E-mail: caissaveloso@yahoo.com.br

**** Graduação em Administração pela Faculdade de Ciências Contábeis de Machado Sobrinho. Mestrado em Administração Pública e Governo pela Fundação Getúlio Vargas - FGV/SP. Doutorado em Economia de L’Empresa pela Universitat Autònoma de Barcelona (Espanha)). Atividade profissional: Professor da Faculdade Pedro Leopoldo/MG. Fundação Pedro Leopoldo. Endereço para correspondência: Av. Lincoln Diogo Viana, 830. CEP: 33600-000 - Pedro Leopoldo - MG (Brasil). Telefone: (31) 3686-1461. E-mail: jedson2010@hotmail.com

**** Graduação em Administração de Empresas pela Universidade Federal de Uberlândia - UFU/MG. Mestrado em Administração de Empresas pela UFU. Doutorando em Administração de Empresas junto à UFMG. Professor da UFU. Endereço para correspondência: Av. João Naves de Ávila, 2121 - Bloco 1F - Sala 216 - Campus Santa Mônica. CEP: 38400-902 - Uberlândia MG (Brasil). Telefone: (34) 3239-4132. E-mail: andrefagundes@fagen.ufu.br

***** Graduação em Administração de Empresas pela Universidade Federal de Juiz de Fora - UFJF/MG. Mestrado em Administração de Empresas pela Universidade Estácio de Sá - UNESA. Doutorado em Administração de Empresas pela UFMG/CEPEAD. Professor da UFJF. Endereço para correspondência: FACC - Campus Universitário, s./n. - Bairro Martelos. CEP: 36036-900 - Juiz de Fora - MG (Brasil). Telefone: (32) 2102-3521. E-mail: danilo.sampaio@ufjf.edu.br
} 


\section{INTRODUÇÃO}

A velocidade das mudanças e disponibilidade de informações faz com que cada vez mais as empresas sejam pressionadas a ter uma leitura rápida do mercado, com respostas precisas que permitam se adaptar e inovar frente a estas mudanças. Nesse aspecto, percebe-se que frequentemente as organizações adotam medidas corretivas em seu cotidiano, o que leva a crer que ao invés de olharem para o futuro visando à antecipação ou previsão das tendências do mercado, estas focam o presente, resolvendo problemas que já aconteceram, devido à falta de uma leitura estratégica do negócio.

A partir desse cenário de turbulências e necessidade constante de adaptação, o marketing de relacionamento se destaca como um meio de se aproximar do cliente, proporcionando a manutenção de relacionamentos duradouros. Por meio do marketing de relacionamento faz-se possível melhorar a qualidade das informações internas e externas necessárias para a tomada de decisão dos gestores e responder questões como: Qual foi seu cliente de ontem? Qual é seu cliente de hoje? Onde o seu cliente estará amanhã? Identificar e conhecer esses clientes, e também manter e captar novos, poderá ser o diferencial frente os concorrentes (KOTLER, 1998).

Considerando que a "indústria hoteleira" no Brasil passa por um momento de reestruturação, devido em parte a eventos esportivos de nível internacional que irão acontecer a partir de 2013, como a Copa das Confederações, torneio teste que antecede a Copa do Mundo de Futebol, a Copa do Mundo de Futebol em 2014 e as Olimpíadas e Paraolimpíadas em 2016, percebe-se a entrada de novos concorrentes no setor. Tal fato, que se faz relevante e importante para o cenário atual, incorre no risco de geração de recessão pós-evento, ou seja, a estrutura e capacidade desta "indústria" se mostrarem maiores do que a demanda pelo serviço efetivamente, o que evoca a discussão acerca da manutenção de um relacionamento duradouro com os clientes.

Nesse contexto de desenvolvimento e incerteza, destaca-se a hotelaria da cidade de Belo Horizonte (Minas Gerais, Brasil), que tem desenvolvido infraestrutura voltada ao turismo de negócios (BELO HORIZONTE, 2012a; MINAS GERAIS, 2012). Segundo dados divulgados pela Associação Brasileira da Indústria Hoteleira (ABIH, 2012), no biênio 2008 e 2009, as taxas médias de ocupação gravitaram em torno de $63 \%$ 
a $68 \%$, com tendência de elevação nos próximos anos, dada a realização de eventos internacionais na capital.

Tais argumentações prospectam a questão que delineia este trabalho, ou seja: "as estratégias de marketing de relacionamento podem ser utilizadas para se gerar vantagem competitiva e garantir níveis satisfatórios de ocupação e de diária médios?”

Para atender ao problema delineado o presente artigo objetiva, por meio de um estudo de caso realizado em um tradicional hotel quatro estrelas localizado no centro da cidade de Belo Horizonte, analisar as percepções dos empregados e clientes acerca das estratégias de marketing de relacionamento adotadas pela gestão. De uma forma mais específica, têm-se como objetivos: a) investigar a percepção dos empregados do hotel sobre as estratégias de marketing de relacionamento adotadas; b) investigar a percepção dos clientes que se hospedam no hotel sobre as estratégias de marketing de relacionamento; c) apresentar uma comparação entre as percepções dos empregados e clientes sobre as referidas estratégias; d) identificar aspectos percebidos como satisfatórios e pontos de melhoria no relacionamento com os clientes.

O artigo está dividido em seis seções, incluindo essa introdução onde foram apresentados o tema, o problema e os objetivos do estudo. Na segunda seção são apresentadas as características do setor hoteleiro de Belo Horizonte, objeto de estudo do trabalho, posteriormente discute-se a importância do marketing de relacionamento para as organizações e a caracterização do marketing de serviços, dado o caráter da organização estudada. Na quarta seção é apresentado o método de coleta de dados, seguida da quinta seção que faz a análise e discussão acerca dos resultados. A última seção apresenta as considerações finais e propostas para estudos futuros.

\section{TURISMO E HOTELARIA EM BELO HORIZONTE}

Belo Horizonte, capital do estado de Minas Gerais, vem se destacando no cenário do turismo de negócios. Sua localização possibilita facilidade de acesso a cidades como Rio de Janeiro, São Paulo, Espírito Santo e Brasília (MINAS GERAIS, 2012). 
Nos últimos dados registrados no site da Associação Brasileira da Indústria Hoteleira de Minas Gerais (ABIH, 2012), Belo Horizonte conta com 103 meios de hospedagem (hotéis) que juntos totalizam 8.365 unidades habitacionais e 18.068 leitos. Ainda segundo a ABIH (2012), a taxa de ocupação gravita em torno de $68 \%$, o que significa que a cada semana em pelo menos cinco dias os meios de hospedagem de Belo Horizonte ficam com ocupação em torno de 100\%. Tais constatações apontam a oportunidade de ampliação do parque hoteleiro da cidade, e projeta um possível gargalo para os períodos posteriores como para os eventos internacionais previstos para ocorrerem no Brasil nos próximos seis anos: a Copa das Confederações em 2013, Copa do Mundo de Futebol em 2014 e os jogos Olímpicos e Paraolímpicos de 2016.

Apesar desse possível gargalo, segundo ABIH (2012) a FIFA (Fédération Internationale de Football Association) solicita para a cidade que irá receber jogos pela Copa do Mundo um mínimo de 3.500 a 4.000 leitos em hotéis de 4 e 5 estrelas para hospedar jogadores, patrocinadores, convidados vips e a imprensa que irá cobrir o evento. Belo Horizonte possui atualmente cerca de 5.000 leitos destas categorias o que atende às exigências da FIFA.

No que diz respeito à capacidade dos hotéis da cidade para receber o publico destes eventos, a ABIH (2012) contabiliza a existência de 34mil leitos em um perímetro de $100 \mathrm{~km}$ do local onde ocorrerão os jogos, neste caso a partir do Estádio do Mineirão em Belo Horizonte.

\section{DO MARKETING AO MARKETING DE RELACIONAMENTO}

A ideia de marketing em algumas empresas é distorcida por se acreditar que o marketing está diretamente relacionado apenas à divulgação, à propaganda e anúncios utilizando mídia impressa ou radiodifusão de seu produto ou serviço. Nesse sentido, faz-se possível inferir que essas organizações acreditam que um grupo de produtos pelo simples fato de serem oferecidos sustentam uma demanda, configurando o que se chama de orientação para a produção (NOVAIS et al., 2010, 2012). Contudo, a abordagem do marketing transcende a divulgação, propaganda e comercialização de um produto ou serviço. Para Kotler, Hayes e Bloom (2002, p. 7) o “[...] marketing é um processo social 
gerencial por meio do qual os indivíduos e os grupos obtêm aquilo de que precisam e também o que desejam em razão da criação e da troca de produtos/ serviços de valor com outras pessoas".

Nesse aspecto ressalta-se a importância do marketing como responsável pela identificação das necessidades e desejos do público alvo, visando por meio deste conhecimento oferecer ao cliente produtos e serviços com a qualidade esperada, garantindo a satisfação do público alvo e consequentemente os objetivos da organização (CHURCHILL JR.; PETER, 2000 e KOTLER, 1998).

Novais et al. $(2010,2012)$ ressaltam que as discussões sobre o papel do marketing não são recentes, pois datam dos anos 1970 e 1980, como divisoras nas mudanças no papel do consumidor, como agente que escolhe. Tais mudanças estariam relacionadas especialmente à disseminação das tecnologias de comunicação e informação, essenciais para o desenvolvimento de uma sociedade interconectada (CASTELLS, 2007), ampliando o painel de escolha dos demandantes de produtos e serviç̧os.

Tais mudanças, “[...] causadas e impulsionadas pelo enorme poder e pela disseminação onipresente da tecnologia" (MCKENNA, 1992, p. 1), induziram a evolução da abordagem do marketing vigente à época, configurando uma transição para aspectos relacionais da comercialização. Com o aumento da concorrência e o aperfeiçoamento da tecnologia, as empresas começam a se preocupar não apenas com a conquista de novos clientes, mas também com a manutenção daqueles já conquistados, dando início ao marketing de relacionamento. Portanto, a manutenção dos clientes já conquistados, ou seja, a adoção de uma estratégia de conservação da carteira de clientes se torna um processo atrativo para as organizações, tendo em vista o custo do processo de captação de potenciais compradores (LARA; PINTO, 2010).

Para Gumensson (1996), o marketing de relacionamento tem três aspectos fundamentais: i) relacionamento; ii) rede; e iii) interação. Para o autor, o processo que envolve esses três aspectos é complexo, dinâmico e interativo. O relacionamento é algo que sugere uma interação entre as partes e cumplicidades. É natural a criação de redes de relacionamento entre organizações quando há interesses comuns e necessidades de atendimento do mercado-alvo. 
"Essa 'nova' abordagem ganha força a partir do momento em que há um reconhecimento geral de que a retenção de cliente é muito menos dispendiosa e significativamente mais lucrativa do que se concentrar na conquista de novos clientes" (LARA; PINTO, 2010, p. 3). Por meio do marketing de relacionamento faz-se possível minimizar riscos provenientes das mudanças do ambiente externo, pois o principal objetivo torna-se a interação entre cliente e organização. Esta interação (conhecimento dos desejos, expectativas e necessidades dos clientes), juntamente com a utilização das informações advindas destes e o domínio sobre tecnologias existentes nos processos, constituem a chave para gerar a confiabilidade necessária para existência de relacionamento duradouro entre as partes (McKENNA, 1992).

Ressalta-se que o a simples manutenção de bancos de dados e programas de fidelidade podem até servir como inibidor da saída do cliente, contudo, esses representam uma visão equivocada do que seja o marketing de relacionamento, que em sua essência representa a orientação para o longo prazo, a construção de vínculos emocionais com os clientes, e a tentativa de se desenvolver a confiança e comprometimento entre as partes (BERRY, 2002).

Para Morgan e Hunt (1994) os relacionamentos baseados na confiança são importantes para as organizações, pois proporcionam compromissos voluntários entre as partes, o que pode conduzir à lealdade dos clientes. Ainda, esses podem representar vantagens uma vez que conduzem a menores custos de operações e divulgação (LOPES et al., 2010).

\subsection{MARKETING DE SERVIÇOS: IMPLICAÇÕES NO SETOR HOTELEIRO}

O Marketing de serviços se assemelha de certo modo ao marketing de produto, embora apresente diferenças próprias. Ambos buscam atingir a satisfação do cliente por meio da troca de bens ou serviços, a diferença entre estas duas modalidades ocorre pela presença de características distintas entre o que é oferecido, ou seja: tangibilidade e intangibilidade; divisibilidade e indivisibilidade; invariabilidade e variabilidade; imperecibilidade e perecibilidade (KOTLER; HAYES; BLOOM, 2002). 
A característica de intangibilidade dos serviços significa que, diferente dos produtos, esses não podem ser observados, provados, cheirados ou ouvidos antes de serem contraídos (HOFFMAN et al., 2010).

Utilizando arquétipos práticos da hotelaria para exemplificar as peculiaridades dos serviços, não se tem o resultado do serviço de hospedagem de um hotel antes que este ocorra. O cliente pode escolher determinada organização pelas experiências de hospedagens anteriores, mas sem dúvida não tem com prever o resultado final da hospedagem em curso (serviço sendo prestado) até que o mesmo se conclua.

Deste modo os novos clientes tentam reduzir a incerteza, por meio da observação e da percepção da qualidade envolvida no serviço, pessoas, equipamentos, informações disponíveis, ou, estrutura física, capital intelectual e humano. Sendo que o "[...] profissional de serviços precisa oferecer uma representação tangível que comunique o processo e os prováveis resultados do serviço que irá prestar" (KOTLER; HAYES; BLOOM, 2002, p. 15).

Por sua vez a característica de indivisibilidade se refere à inexistente possibilidade de separação do serviço e de quem o presta, pela percepção do cliente. Diferente do bem, que é passível de separação entre a organização que o comercializa e a sua qualidade (ZEITHAML; BITNER; GREMLER, 2011).

Retornando ao objeto de estudo, no setor hoteleiro o serviço tem essa percepção parelha de forma que o recepcionista de um hotel pode influenciar positivamente ou negativamente na avaliação do cliente. É difícil separar o atendimento prestado do serviço de hospedagem, visto que ambos são parte do serviço contratado.

Já a característica da variabilidade define que, sendo o serviço inseparável da pessoa que o presta, e pela existência de fatores humanos envolvidos neste, o serviço pode mudar de cliente para cliente, ou seja, o modo que um recepcionista trata o cliente "A" pode ser diferente do modo em que o mesmo recepcionista trata o cliente "B". Essa diferença pode ser minimizada por meio de treinamentos, feedback dos clientes e da própria gerência, mas nunca deixaram de existir (HOFFMAN et al., 2010).

A característica da perecibilidade dos serviços denota que o mesmo não pode ser armazenado diferentemente do bem, pois o serviço é preparado e consumido no mesmo espaço de tempo (LOVELOCK; WRIGHT, 2006). 
Um exemplo clássico na hotelaria se dá com as reservas de apartamentos. A programação de serviços a ser realizado na data "x" não pode ser armazenada para utilização na data "y". O que define essa afirmativa é o fato de existir uma capacidade (limite) de fornecimento do serviço, caso os clientes que reservaram apartamentos na data " $x$ " não utilizem este serviço nesta data, o hotel não ira recuperar a perda desta capacidade de fornecimento em data distinta.

Quanto a não possibilidade de avaliação prévia, ressalta-se possíveis diferenças quanto a critérios estabelecidos para a satisfação entre bens e serviços. Zeithaml, Bitner e Gremler (2011) descrevem que pela existência característica da perecibilidade é impossível se ter uma avaliação prévia do que se está adquirindo, pela produção e consumo simultâneo após a venda. Já o bem por ser tangível e passível de armazenamento, pode possibilitar a identificação de aspectos de interesse do consumidor antes de ser concretizada a compra. Por exemplo, em um automóvel podese fazer um test drive antes da aquisição, enquanto na compra de uma diária em um hotel é difícil prever se o resultado será satisfatório sem que haja o consumo do serviço adquirido.

Para Kotler, Hayes e Bloom (2002, p. 17) "[...] cada experiência gera uma impressão acerca do serviço, conhecida como o momento da verdade”. Estes momentos da verdade são os segundos que limitam a criação da impressão a respeito da qualidade do serviço, sendo que este segundo depende da capacidade humana da linha de frente em fornecer uma mensagem coerente, assertiva e positiva quanto à qualidade do serviço que está sendo oferecido ao cliente. Para Hoffman e Bateson (2001) os consumidores avaliam o desempenho de serviços utilizando dois padrões que transitam entre o nível de serviços desejado e o nível de serviços adequado. Entre estes dois, há o que se chama "zona de tolerância", que não representa o que está perfeito, mas aceitável - aos olhos do consumidor -, em determinadas circunstâncias (HOFFMAN; BATESON, 2001). Esta zona de tolerância é variável e depende de fatores como o perfil do cliente e tipos de compras realizadas por estes. 


\section{ASPECTOS METODOLÓGICOS}

O presente trabalho, de abordagem predominante quantitativa, se classifica quanto aos fins como uma pesquisa descritiva. As pesquisas descritivas quantitativas, segundo Hair Jr. et al. (2010, p. 133) se caracterizam “[...] no sentido usarem números e estatísticas para resumir demografias, atitudes e comportamentos". Para Churchill Jr. (1987), a pesquisa descritiva procura conhecer e interpretar a realidade sem nela interferir.

Quanto aos meios, a pesquisa se classifica como um estudo de caso, por permitir a identificação, exploração e estudo de determinado processo em uma organização. A escolha do estudo de caso se respalda em Yin (2001), que aponta o método como sendo uma investigação que possibilita gerar uma pesquisa respaldada nos movimentos presentes dentro do contexto da vida real, especialmente quando os limites entre esse contexto e os movimentos estão claramente definidos por fatores do cotidiano.

A organização escolhida para observação e estudo, aqui chamada de empresa Alfa para garantir a confidencialidade das informações, tem sede na cidade de Belo Horizonte e constitui uma rede hoteleira com dois empreendimentos na região.

Utilizou-se o recurso de questionário estruturado de dois tipos, um direcionado aos clientes internos e outro aos clientes externos. A pesquisa foi aplicada para os empregados da rede hoteleira no mês de novembro de 2011, quando foram entrevistados 15 funcionários.

Os questionários de clientes foram aplicados no mês de outubro de 2011. Esses foram preenchidos no momento de sua entrega, a fim de evitar qualquer influência de terceiros na resposta dada pelo respondente. Totalizou-se 120 questionários aplicados nessa modalidade.

Ainda buscando identificar à importância que é dada a opinião e informação fornecida pelos clientes, foi realizada uma pesquisa documental, que compreendeu a análise de opinários de hóspedes (ferramenta elaborada para coletar informações e que possibilita ao hóspede sugerir melhorias no serviço e opinar sobre sua estadia, pontuando pontos fracos e fortes) dos anos de 2009 e 2010. 


\section{RESULTADOS E ANÁLISE}

Nessa seção são apresentados os resultados das pesquisas realizadas com os clientes externos e internos da organização estudada, para as devidas inferências. Inicialmente é apresentado o perfil dos hóspedes pesquisados, com informações socioeconômicas e intenção de futura hospedagem.

Em seguida são apresentadas as informações sobre os serviços de hospedagem e, na sequência, a análise dos opinários, que são considerados instrumentos de direcionamento para as ações de pós-marketing. Por fim, apresentam-se a análise dos questionamentos aos clientes internos, onde se objetivou identificar aspectos que envolvam a interação e/ou o relacionamento desses com os clientes externos.

\subsection{PERFIL DOS CLIENTES}

Durante o período pesquisado foi possível coletar informação de 120 hóspedes, sendo $81 \%$ do sexo masculino e $19 \%$ do sexo feminino. Fez-se predominante um público com idade superior a 25 anos, sendo que a maior concentração neste quesito se deu a partir de pessoas com faixa etária entre 26 e 35 ou acima de 46 anos, o equivalente a $34 \%$ e $33 \%$ respectivamente. Os hóspedes com idade até 25 anos corresponderam a $7 \%$ e entre 36 e 45 anos a $26 \%$ do total de entrevistados. Quanto às profissões dos entrevistados as respostas mais frequentes foram: vendedor com 17\%; segurança, também com 17\%; e, engenheiro com 13\% dos questionários respondidos.

Mais da metade dos respondentes, o equivalente a $60 \%$, já havia se hospedado no Hotel Alfa anteriormente, sendo que $27 \%$ afirmaram ultrapassar a décima estadia. Quando questionados sobre o motivo da estadia, $72 \%$ afirmaram que estavam a negócios ou eventos, sendo que apenas $4 \%$ afirmaram estar a passeio, o que corrobora com as proposições do turismo belorizontino voltado aos negócios.

Questionados sobre a possibilidade de voltar a se hospedar no hotel, 78\% afirmaram que esta seria alta ou muito alta, sendo negócios a justificativa mais assinalada, com $45 \%$ das respostas. 


\subsection{SOBRE SERVIÇOS DE HOSPEDAGEM}

Em relação aos serviços de hospedagem, buscou-se compreender: a) relevância dos fatores para escolha por este hotel; b) grau de melhora que este fator deverá sofrer; e c) grau de melhora do fator desde sua primeira estadia (este último quesito se fez necessário somente para hóspedes com mais de uma hospedagem no hotel).

Os fatores abordados foram: adoção de tarifas diferenciadas, atendimento e cortesia, autonomia de funcionários, variedade em serviços (cortesia de café da manha, internet, garagem, dentre outros), localização estratégica, gerenciamento de informações vindas dos clientes, reputação positiva do hotel, excelência em acomodação e restaurante. Utilizou-se para tanto a escala Likert (HAIR JR. et al., 2010), variando de alta a nenhuma, conforme Tabela 1.

TABELA 1 - FATORES RELEVANTES PARA A ESCOLHA POR ESTE HOTEL

\begin{tabular}{l|c|c|c|c|c}
\multicolumn{1}{c}{ Fatores } & Alta & Muita & Indiferente & Baixa & Nenhuma \\
\hline \multirow{2}{*}{ Adoção de tarifas diferenciadas } & $44,17 \%$ & $30,83 \%$ & $20,00 \%$ & $1,67 \%$ & $3,33 \%$ \\
\cline { 2 - 6 } & 53 & 37 & 24 & 2 & 4 \\
\hline \multirow{2}{*}{ Atendimento/Cortesia } & $65,00 \%$ & $30,83 \%$ & $4,17 \%$ & - & - \\
\cline { 2 - 6 } & 78 & 37 & 5 & - & - \\
\hline \multirow{2}{*}{ Autonomia dos funcionários } & $28,33 \%$ & $49,17 \%$ & $20,83 \%$ & $0,83 \%$ & $0,83 \%$ \\
\cline { 2 - 6 } & 34 & 59 & 25 & 1 & 1 \\
\hline \multirow{2}{*}{ Variedades em serviços } & $49,17 \%$ & $44,17 \%$ & $4,17 \%$ & $0,83 \%$ & $1,67 \%$ \\
\cline { 2 - 6 } & 59 & 53 & 5 & 1 & 2 \\
\hline \multirow{2}{*}{ Localização estratégica } & $67,50 \%$ & $28,33 \%$ & $2,50 \%$ & $0,83 \%$ & $0,83 \%$ \\
\hline \multirow{2}{*}{$\begin{array}{l}\text { Gerenciamento de informações } \\
\text { vinda dos hospedes }\end{array}$} & 81 & 34 & 3 & 1 & 1 \\
\hline \multirow{2}{*}{ Reputação do hotel } & $12,50 \%$ & $49,17 \%$ & $33,33 \%$ & $1,67 \%$ & $3,33 \%$ \\
\hline \multirow{2}{*}{ Excelência em acomodações } & $15,00 \%$ & $45,00 \%$ & $34,17 \%$ & $3,33 \%$ & $2,50 \%$ \\
\hline \multirow{2}{*}{\begin{tabular}{l} 
Restaurante \\
\cline { 2 - 6 }
\end{tabular}} & 18 & 54 & 41 & 4 & 3 \\
\hline
\end{tabular}

FONTE: DADOS DA PESQUISA / ELABORADO PELOS AUTORES (2012).

Ao se analisar a Tabela 1, constata-se que os respondentes indicaram como sendo de alta relevância para sua escolha de se hospedar no hotel os fatores: adoção de tarifas diferenciadas; atendimento e cortesia; variedade de serviços; e localização estratégica, enquanto os fatores autonomia dos funcionários, gerenciamento de informações vinda dos hóspedes, reputação do hotel, excelência em acomodações e 
restaurante foram considerados muito relevantes. Foi verificado que as maiores incidências de respostas ficaram entre estas classificações, sendo que as exceções se deram somente nos fatores reputação do hotel, restaurante e gerenciamento das informações vindas de hóspedes que apresentaram como segunda maior frequência de resposta a opção indiferente.

Em continuidade, questionou-se o quanto os serviços deveriam ser melhorados. Ao analisar os fatores apresentados na Tabela 2, e a percepção de melhora observada pelos clientes, houve uma maior concentração de respostas na opção razoavelmente, sendo que a exceção se deu no fator localização estratégica que teve o maior número de respostas na opção de nenhuma melhora, justificado uma vez que esse item foi anteriormente indicado como favorável ao empreendimento. Foi verificado que as maiores incidências de respostas ficaram entre as classificações, razoavelmente, pouca ou nenhuma melhora, o que pode ser considerado bom, sendo possível inferir que os clientes demonstraram satisfação em relação aos aspectos apresentados.

TABELA 2 - QUANTO DEVEM SER MELHORADOS OS SERVIÇOS

\begin{tabular}{|c|c|c|c|c|c|}
\hline Fatores & $\begin{array}{l}\text { Altamente } \\
\text { melhorado }\end{array}$ & Muito & Razoavelmente & Pouca & $\begin{array}{c}\text { Nenhuma } \\
\text { melhora }\end{array}$ \\
\hline \multirow{2}{*}{ Adoção de tarifas diferenciadas } & $15,00 \%$ & $26,67 \%$ & $39,17 \%$ & $15,00 \%$ & $4,17 \%$ \\
\hline & 18 & 32 & 47 & 18 & 5 \\
\hline \multirow{2}{*}{ Atendimento/Cortesia } & $10,00 \%$ & $15,00 \%$ & $35,83 \%$ & $26,67 \%$ & $12,50 \%$ \\
\hline & 12 & 18 & 43 & 32 & 15 \\
\hline \multirow{2}{*}{ Autonomia dos funcionários } & $8,33 \%$ & $13,33 \%$ & $47,50 \%$ & $22,50 \%$ & $8,33 \%$ \\
\hline & 10 & 16 & 57 & 27 & 10 \\
\hline \multirow[b]{2}{*}{ Variedades em serviços } & $15,83 \%$ & $25,00 \%$ & $28,33 \%$ & $21,67 \%$ & $9,17 \%$ \\
\hline & 19 & 30 & 34 & 26 & 11 \\
\hline \multirow{2}{*}{ Localização estratégica } & $10,83 \%$ & $14,17 \%$ & $23,33 \%$ & $21,67 \%$ & $30,00 \%$ \\
\hline & 13 & 17 & 28 & 26 & 36 \\
\hline \multirow{2}{*}{$\begin{array}{l}\text { Gerenciamento de informações } \\
\text { vinda dos hospedes }\end{array}$} & $9,17 \%$ & $8,33 \%$ & $44,17 \%$ & $20,00 \%$ & $18,33 \%$ \\
\hline & 11 & 10 & 53 & 24 & 22 \\
\hline \multirow{2}{*}{ Reputação do hotel } & $10,00 \%$ & $14,17 \%$ & $40,00 \%$ & $25,83 \%$ & $10,00 \%$ \\
\hline & 12 & 17 & 48 & 31 & 12 \\
\hline \multirow{2}{*}{ Excelência em acomodações } & $14,17 \%$ & $25,83 \%$ & $34,17 \%$ & $15,83 \%$ & $10,00 \%$ \\
\hline & 17 & 31 & 41 & 19 & 12 \\
\hline \multirow{2}{*}{ Restaurante } & $10,00 \%$ & $26,67 \%$ & $29,17 \%$ & $26,67 \%$ & $7,50 \%$ \\
\hline & 12 & 32 & 35 & 32 & 9 \\
\hline
\end{tabular}

FONTE: DADOS DA PESQUISA / ELABORADO PELOS AUTORES (2012).

Em continuidade, perguntou-se a aqueles hóspedes que já haviam se hospedado anteriormente no hotel Alfa sobre uma possível melhora dos serviços desde a última estadia. Ao analisar os fatores apresentados na Tabela 3 e o grau de melhora 
apresentado desde a primeira hospedagem, a opção razoavelmente, foi indicada nos fatores: adoção de tarifas diferenciadas, atendimento e cortesia, autonomia dos funcionários, gerenciamento de informações vinda dos hóspedes, excelência em acomodações. Ressalta-se a variável "variedades em serviços para os clientes", percebida como pouca melhora.

TABELA 3 - GRAU DE MELHORA DOS FATORES DESDE A PRIMEIRA ESTADIA NO HOTEL

\begin{tabular}{l|c|c|c|c|c}
\multicolumn{1}{c|}{ Fatores } & $\begin{array}{c}\text { Altamente } \\
\text { melhorado }\end{array}$ & Muito & Razoavelmente & Pouca & $\begin{array}{c}\text { Nenhuma } \\
\text { melhora }\end{array}$ \\
\hline \multirow{2}{*}{ Adoção de tarifas diferenciadas } & $11,67 \%$ & $10,00 \%$ & $33,33 \%$ & $15,00 \%$ & $30,00 \%$ \\
\cline { 2 - 6 } & 7 & 6 & 20 & 9 & 18 \\
\hline \multirow{2}{*}{ Atendimento/Cortesia } & $18,33 \%$ & $23,33 \%$ & $30,00 \%$ & $18,33 \%$ & $10,00 \%$ \\
\cline { 2 - 6 } & 11 & 14 & 18 & 11 & 6 \\
\hline \multirow{2}{*}{ Autonomia dos funcionários } & $10,00 \%$ & $25,00 \%$ & $38,33 \%$ & $11,67 \%$ & $15,00 \%$ \\
\cline { 2 - 6 } & 6 & 15 & 23 & 7 & 9 \\
\hline \multirow{2}{*}{ Variedades em serviços } & $21,67 \%$ & $11,67 \%$ & $20,00 \%$ & $28,33 \%$ & $18,33 \%$ \\
\cline { 2 - 6 } & 13 & 7 & 12 & 17 & 11 \\
\hline \multirow{2}{*}{$\begin{array}{l}\text { Localização estratégica } \\
\text { Gerenciamento de informações }\end{array}$} & $11,67 \%$ & $16,67 \%$ & $21,67 \%$ & $6,67 \%$ & $43,33 \%$ \\
\cline { 2 - 6 } & 7 & 10 & 13 & 4 & 26 \\
\hline \multirow{2}{*}{ Reputação do hotel } & 4 & 11 & 20 & 7 & 18 \\
\hline \multirow{2}{*}{ Excelência em acomodações } & $8,33 \%$ & $23,33 \%$ & $23,33 \%$ & $8,33 \%$ & $36,67 \%$ \\
\hline \multirow{2}{*}{ Restaurante } & 5 & 14 & 14 & 5 & 22 \\
\hline
\end{tabular}

FONTE: DADOS DA PESQUISA / ELABORADO PELOS AUTORES (2012).

\subsection{PÓS-MARKETING}

Buscando-se avaliar o pós-marketing da organização, foram analisados os opinários com o intuito de identificar nos processos e serviços da organização melhorias sugeridas pelos clientes. Para tanto, destaca-se o papel do setor responsável pelo pósmarketing, que elabora as respostas às questões abordadas. Foram preenchidos 326 opinários entre janeiro e outubro de 2010, sendo que cerca de $90 \%$ destes foram retornados. O motivo declarado pelos empregados responsáveis pela falta de retorno dos $10 \%$ restantes foi a dificuldade de contato com o respondente.

Constatou-se que essa ferramenta é considerada pela organização como importante, sendo que as sugestões por ela angariadas são analisadas e, em muitos casos, passam a constituir para o planejamento estratégico do Hotel Alfa, sendo 
implantadas ao longo do ano seguinte, sempre que julgadas pertinentes, conforme a prioridade estabelecida em votação da diretoria e gerência.

\subsection{ANÁLISE DOS DADOS: CLIENTES INTERNOS}

Durante o período das entrevistas coletou-se informações de 15 empregados da organização, sendo dez mulheres. Em uma classificação de acordo com o cargo ocupado na organização, foram entrevistados: quatro camareiras; quatro recepcionistas; três agentes de reserva; um gerente de hospedagem e um auxiliar de governança.

Quando perguntados se a organização adotava medidas para motivar a criação e manutenção do relacionamento com clientes, $100 \%$ afirmaram que sim, descrevendo que isso ocorria pelo retorno de todos os opinários por meio do telemarketing, com atendimento personalizado e busca de melhoria dos fatores indicados pelos clientes, demonstrando preocupação e atenção à opinião dos clientes.

Ao se questionar sobre a existência de treinamento ou orientação para a execução de procedimentos ligados a coleta ou tratamento das informações vindas dos clientes, $100 \%$ responderam que havia treinamento, sendo que todos os setores se faziam responsáveis por prezar a qualidade do serviço. Nesse aspecto, os entrevistados manifestaram entender que a satisfação dos clientes com o atendimento depende da interação e da prestação de serviço de qualidade em todos os níveis da estadia, desde o contato para efetuar a reserva até o check out (saída do hóspede).

Foram elencados os itens: adoção de tarifas diferenciadas; atendimento e cortesia; autonomia de funcionários; variedade em serviços (cortesia de café da manha, internet, garagem, dentre outros); localização estratégica; gerenciamento de informações vindas dos clientes; reputação positiva do hotel e excelência em acomodação. Em seguida, perguntou-se sobre a importância destes para a criação de relacionamento entre hotéis (de forma generalizada) e clientes. O mesmo questionamento foi realizado utilizando-se a empresa Alfa como ponto de análise. Nesse quesito, a autonomia dos funcionários foi considerada como prevalecente e fator diferenciador do hotel Alfa. 


\section{CONSIDERAÇÕES FINAIS}

Vislumbra-se que o cenário hoteleiro brasileiro passará por mudanças devido aos eventos internacionais esportivos que irão acontecer neste país nos anos de 2013, 2014 e 2016 sendo estes, a Copa das Confederações, Copa do Mundo de Futebol, Olimpíadas e Paraolimpíadas respectivamente. Algumas destas mudanças já são visíveis, como a estruturação física dos empreendimentos hoteleiros (criação de novos empreendimentos e reformas estruturais) e a preocupação com a capacitação da mão de obra.

O presente artigo buscou analisar a utilização do marketing de relacionamento em uma organização do ramo hoteleiro, na região metropolitana de Belo Horizonte, visando identificar a criação de vantagem competitiva, garantia de níveis satisfatórios de ocupação e de diária médios devido à utilização dos preceitos de marketing de relacionamento.

A partir dos resultados obtidos considerou-se possível inferir que as ações de marketing de relacionamento têm contribuído na manutenção dos resultados de ocupação, uma vez que, analisando este por meio da utilização da tarifa habitue (tarifa praticada com empresa, agências de turismo e clientes que detém relacionamento com a organização) foi verificado que a prática da aplicabilidade desta tarifa equivale a $74,77 \%$ de todas as reservas do hotel no período estudado.

Quanto á diária média, o marketing de relacionamento pode auxiliar na manutenção de uma diária satisfatória, mas ao se considerar o cenário no qual a oferta é maior que a demanda esta ferramenta não favorece a manutenção de níveis satisfatórios, uma vez que a oferta elevada e a pouca demanda puxariam os preços praticados para baixo.

Analisando-se a ocupação da organização, que foi de 60,47\% no ano de 2010 (dados fornecidos pela organização), e comparando-a com o segmento hoteleiro de Belo Horizonte, que gravitou em torno de 67,95\% (BELO HORIZONTE, 2012b), tendo como base o mesmo ano, foi identificado que a organização estudada apresentou um percentual de ocupação abaixo da apresentada no mercado hoteleiro, gerando assim capacidade produtiva ociosa. Segundo dados fornecidos pela organização estudada, em apenas 4 dias o hotel apresenta ocupação máxima de 100\%, gerando assim capacidade 
produtiva ociosa de 3 dias, o que diverge do segmento na cidade, que apresenta ocupação máxima durante 5 dias na semana.

Apesar dos dados de ocupação não atingirem o patamar do setor, constatou-se haver relacionamento entre empresa e cliente, uma vez $74 \%$ desta ocupação foi composta por hóspedes que retornam ao estabelecimento.

Após o estudo do marketing de relacionamento nesta organização identifica-se que para manutenção e ampliação dos resultados faz-se necessário além da continuidade das práticas de criação de relacionamento com os clientes, avançar e aproveitar a ociosidade da capacidade de produção, uma vez que a organização tem possibilidade de aumentar em 39,53\% a sua taxa de ocupação.

Nesse sentido, além da manutenção dos clientes atuais, faz-se importante também adotar práticas de captação de novos clientes. Como limitações, acredita-se que os resultados poderiam ser melhor apurados se estendido o prazo de aplicação do questionário durante períodos diversificados no mês.

Como sugestão para estudos futuros inclui-se a possibilidade de ampliar a pesquisa, disponibilizando o questionário on line $\mathrm{e}$ aplicando-o a outros empreendimentos do setor, como forma de comparar as informações coletadas.

\section{REFERÊNCIAS}

ABIH - Associação Brasileira da Indústria Hoteleira. Números oficiais da Hotelaria na Região de Belo Horizonte. ABIH, out. 2009. Disponível em: <http://www.abihmg.com.br/abih_novo/dados.asp>. Acesso em: 19/05/2012.

BELO HORIZONTE. Programa de Turismo de Negócios e Eventos. Disponível em: <http://www.belohorizonte.mg.gov.br/negocios/cidade-para-os-negocios/programa-deturismo-de-negocios-e-eventos>. Acesso em: 21/09/2012a.

BELO HORIZONTE. Estatística e Indicadores. Disponível em: $<$ http://portalpbh.pbh.gov.br/pbh/ecp/comunidade.do?evento=portlet\&pIdPlc=ecpTaxon omiaMenuPortal\&app=estatisticaseindicadores\&tax=20041\&lang=pt_BR\&pg=7742\&t axp=0\&>. Acesso em 19/09/2012b.

BERRY, L. Relationship Marketing of Services - Perspectives from 1983 and 2000. Journal of Relationship Marketing, v. 1, n. 1, p. 59-77, 2002.

CASTELLS, M. A sociedade em rede. 11. ed. São Paulo: Paz e Terra, 2007. 
CHURCHILL JR., G. A.; PETER, J. P. Marketing: criando valor para o cliente. 2. ed. São Paulo: Saraiva, 2000.

CHURCHILL, JR., G. A. Marketing Research: Methodological Foundations. Chicago: The Dryden Press, 1987.

GUMMESSON, E. Relationship marketing and imaginary organizations: a synthesis. European Journal of Marketing, v. 30, n. 3, p. 31-34, 1996.

HAIR JR., J.; WOLFINBARGER, M.; ORTINAU, D. J.; BUSH, R. P. Fundamentos de Pesquisa de Marketing. Porto Alegre: Bookman, 2010.

HOFFMAN, K. D.; BATESON, J. E. G. Marketing de Serviços. 4. ed. Porto Alegre: Bookman, 2001.

HOFFMAN, K. D.; BATESON, J. E. G.; IKEDA, A. A.; CAMPOMAR, M. C. Princípios de Marketing de Serviços: conceitos, estratégias e casos. 3. ed. São Paulo: Cengage Learning, 2010.

KOTLER, P. Administração de marketing: análise, planejamento, implementação e controle. 4. ed. São Paulo: Atlas, 1998.

KOTLER, P.; HAYES,T.; BLOOM, P. N. Marketing de Serviços Profissionais: estratégias inovadoras para impulsionar sua atividade, sua imagem e seus lucro. 2. ed. São Paulo: Manole, 2002.

LARA, J. E.; PINTO, M. R. Marketing de Relacionamento no Mercado Consumidor em uma Perspectiva Experiencial e Simbólica: Buscando Novas Proposições para Pesquisa. In: ENCONTRO DE MARKETING DA ANPAD (EMA), 4, 2010. Florianópolis. Anais... Florianópolis: Anpad, 2010. p. 1-17.

LOPES, E. L.; FURRIER, M. T.; PIZZINATTO, N. K.; CUNHA, R. A. N. Táticas Vinculantes em Marketing de Relacionamento: Um Estudo Aplicado ao Varejo de Construção e Decoração Brasileiro nos Formatos Tradicional e Virtual. In: ENCONTRO DE MARKETING DA ANPAD (EMA), 4, 2010. Florianópolis. Anais... Florianópolis: Anpad, 2010. p. 1-17.

LOVELOCK, C.; WRIGHT, L. Serviços: marketing e gestão. 6. ed. São Paulo: Saraiva, 2006.

McKENNA, R. Marketing de relacionamento: estratégias bem-sucedidas para a era do cliente. Rio de Janeiro: Campus, 1992.

MINAS GERAIS. Negócios. Disponível em: <http://www.minasgerais.com.br/segmentos/negocios/>. Acesso em: 21/09/12. 
MORGAN, R. M.; HUNT, S. D. The commitment-trust theory of relationship marketing. Journal of Marketing, n. 58, p. 20-38, jul. 1994.

NOVAIS, F. C.; SOUSA, C. V.; MELO, J. M. C.; SANTOS, F. L. Marketing Relacionado as Causas como Vantagem Competitiva: um estudo com jovens universitários na cidade de Belo Horizonte. In: XIII SEMEAD - SEMINÁRIOS EM ADMINISTRAÇÃO. Set de 2010. Anais... São Paulo: Semead, 2010. p. 1-16.

NOVAIS, F. C.; SOUSA, C. V.; LARA, J. E.; MELO, J. M. C.; SANTOS, F. L. Análise das Estratégias de Marketing Associadas a Causas Sociais: um estudo na cidade de Belo Horizonte. ReFAE - Revista da Faculdade de Administração e Economia, v. 3, n. 2, p. 32-55, 2012.

YIN, R. K. Estudo de Caso: Planejamento e métodos. 2. ed. Porto Alegre: Ed. Bookman, 2001.

ZEITHAML, V. A.; BITNER, M. J.; GREMLER, D. D. Marketing de Serviços: a empresa com foco no cliente. 5. ed. Porto Alegre: Bookman, 2011.

Recebido em: 22-05-2012.

Aprovado em: 22-06-2012. 